RESEARCH AND PRACTICE

\title{
Differences in health literacy knowledge and experiences among senior nursing students
}

\author{
Sharon S. Williamson, MPH, DrPH, CHES ${ }^{1}$ and Joanne Chopak-Foss, PhD, FASHA² \\ ${ }^{1}$ Jiann-Ping Hsu College of Public Health, Georgia Southern University, Statesboro, Georgia; ${ }^{2}$ Jiann-Ping Hsu College of Public Health, \\ Georgia Southern University, Statesboro, Georgia
}

\begin{abstract}
Background: Low health literacy has been identified as a significant public health problem. Also, higher expenditures due to longer hospital stays have been reported for persons with low health literacy. Nurses can assist patients with low health literacy to reduce their hospital stays and increase compliance with discharge instructions.
\end{abstract}

Methods: A quantitative, descriptive research design was employed to assess knowledge and experiences of 192 senior nursing students. These students were administered the Health Literacy Knowledge and Experiences Survey (HL-KES), a 2part survey that included assessment of knowledge about health literacy and experience in working with populations of low health literacy. Additional questions to assist in describing the sample population were included. Analysis of variance (ANOVA) and post-hoc tests were used to measure differences.

Results: The results reveal that, at this point in their nursing education, senior nursing students lack health literacy knowledge and experiences. Statistically significant differences were found for health literacy knowledge among participants in the same program and for those enrolled at different program sites. Differences were found for health literacy experiences among participants, but these were not statistically significant due to unequal sample sizes between BSN and RN to BSN, and LPN/LVN to BSN participants.

Conclusions: Regardless of program site, senior nursing students have some health literacy knowledge, but gaps exist. Mean scores for health literacy knowledge varied for participants and as a whole for program sites. Thus, differences in health literacy knowledge are most likely the result of how health literacy is addressed by different programs.

Keywords: health literacy, knowledge, experiences, nursing students, nursing programs, patient education

\section{INTRODUCTION}

The ability to obtain health information, understand health information, and interpret health information is the widely accepted definition of health literacy (IOM, 2004). The Healthy People 2020 initiative and the United States Department of Health and Human Services have included it as a new topic, with objectives for addressing it in the decade to come (Retrieved from http://www.healthypeople.gov).

Up to half of patients cannot comprehend basic healthcare information (IOM, 2004; Joint Commission, 2007). According to the Center for Healthcare Strategies (1997), low health literacy hinders successful treatment regimens and increases the risk of medical errors because of poor understanding of health information. In 2007, the Joint Commission published "What Did the Doctor Say? Improving Health Literacy to Protect Patient Safety.” The report recommended use of various interventions, such as simplified information and illustrations, avoiding jargon, "teach-back" methods, and encouraging questions from patients as ways to improve health behaviors in persons with low health literacy.
Health literacy is gaining greater attention in clinical care settings and other healthcare communities (Egbert \& Nanna, 2009). Recent studies suggest that nurses are not adequately prepared for affecting changes in health literacy (Smith \& Zsoher, 2011). Several reports have indicated that knowledge of consequences associated with poor health literacy skills and evaluation of health literacy interventions is low, suggesting that nursing students enter the workforce with knowledge gaps related to identifying populations of low health literacy, conducting health literacy screenings, and implementing health literacy interventions (Cafiero, 2012; Cormier \& Kotrlik, 2009; Knight, 2010).

Lack of health literacy knowledge affects nurses at all levels, from pre-licensure to practice. Sand-Jecklin, Murray, Summers, and Watson (2010), along with national nursing organizations, suggest that nurses' health literacy knowledge and experiences are enhanced if health literacyrelated content is incorporated into the nursing education curriculum (Smith \& Zsohar, 2011). Cornett (2009) identified objectives, content outlines, and clinical activities that could be integrated into the nursing curriculum. Other researchers found that undergraduate nursing students 
understood the impact of low health literacy on patient health outcomes, but lacked knowledge of its impact on the healthcare system (Jukkala, Deupree, \& Graham, 2009). Education and training programs designed for nursing students are needed if the problem of low health literacy is to be addressed.

Information about the health literacy knowledge, experiences, and skills among undergraduate and diploma nursing student practitioners is limited (Alper, 2015; Coleman, 2011; Cooper, 2011; Scheckel et al., 2010), and because health literacy content in the nursing curriculum is inconsistent, no study has investigated the current practices of preparing nursing students to improve the health literacy skills of their future patients.

The purpose of this study was to extend existing research by investigating differences in health literacy knowledge and experiences among senior nursing students, specifically in Bachelor of Science in Nursing (BSN) and Registered Nurse (RN) to BSN programs. Students in the Licensed Practical Nurse (LPN)/Licensed Vocational Nurse (LVN) to BSN programs were included in the sample. Comparisons on health literacy knowledge among nursing students within and between program sites were made.

\section{METHODS}

A quantitative, descriptive, cross-sectional survey research design was utilized to assess health literacy knowledge and experiences among senior nursing students. The following questions guided the study:

1. Do differences exist in health literacy knowledge among senior nursing students in the same program?

2. Do differences exist in health literacy knowledge among nursing students enrolled at different programs sites?

3. Are there differences in health literacy experiences among senior nursing students?

\section{Study Population}

The sample for this study was selected from senior nursing students enrolled in the Bachelor of Science in Nursing (BSN), Registered Nurse (RN) to Bachelor of Science in Nursing (BSN), and Licensed Practical Nurse (LPN) and Licensed Vocational Nurse (LVN) to Bachelor of Science in Nursing (BSN) programs in Southeast Georgia, Central Georgia, and South Carolina Low Country areas. Most (95\%) were pre-licensure, $\mathrm{RN}$ to BSN students. Table 1 displays the numbers and percentages of nursing students by degree program. Most of the participants had completed at least one semester/quarter of clinical placement. For the universities, program enrollments ranged from 9 to 50 students. Programs with two or more classes were combined. The population-sampling frame was 323. Two hundred students completed the survey. However, due to the small sample size of one program site, adjustments were made to the sample size from 200 to 192, leading to a response rate of $59 \%$ in order to make cross-program comparisons.

\begin{tabular}{|c|l|c|c|}
\hline \multicolumn{4}{|c|}{ Table 1. Nursing Programs by Degreed Programs } \\
\hline $\begin{array}{c}\text { Nursing } \\
\text { Program }\end{array}$ & \multicolumn{1}{|c|}{ Degree Type } & $\mathbf{n = 1 9 2}$ & $\mathbf{\%}$ \\
\hline Program 1 & BSN, RN-BSN, LPN-BSN & 45 & $19 \%$ \\
\hline Program 2 & BSN, RN-BSN & 17 & $9 \%$ \\
\hline Program 3 & BSN, RN-BSN, LPN-BSN & 29 & $15 \%$ \\
\hline Program 4 & BSN, RN-BSN, LPN-BSN & 88 & $44 \%$ \\
\hline Program 5 & BSN, RN-BSN & 20 & $10 \%$ \\
\hline
\end{tabular}

\section{Instrument}

The Health Literacy Knowledge and Experience Survey (HL-KES) (Cormier \& Kotrlik, 2009) was used to measure the health literacy knowledge and experiences of the nursing students. The original survey was designed to measure health literacy knowledge and experiences among practicing nurses.

Part I of the instrument, measuring health literacy knowledge, is composed of 29 multiple-choice questions designed to capture information about participants' knowledge of health literacy in five content areas. Questions focused on the following specific content areas: Six items measured basic facts related to health literacy. A sample question was, "Low health literacy levels are most prevalent among which of the following age groups?" Four items measured consequences associated with low health literacy. A sample question asked about the respondents' ability to recognize a patient with low health literacy skills. Six items measured health literacy screening. A sample question examining knowledge about health literacy screening was, "Which of the following questions would provide a nurse with the best estimate of a patient's reading skills?” Eleven items in the Knowledge section measured responses on guidelines for written healthcare materials. One question specific to the respondents' knowledge about guidelines was "The best way to ensure that a breast cancer prevention brochure is culturally appropriate is to:" Answering the question correctly indicated that the respondent understood the guidelines for written health care materials. Lastly, two items measured evaluation of health literacy interventions and were each sub-categorized as application cognitive level. One question from this section explored "The most effective way for a nurse to determine how well a patient with low health literacy skills understands health care information."

The second part of the survey measured health literacy experiences. The original survey (Cormier, 2006) was developed in 2005. Three questions related to the delivery of health information were omitted from data collection due to changes in how health information is delivered since the time of development of the initial survey. Specifically, questions about the use of videotapes, audiotapes, and written healthcare materials were excluded from the current study. Questions in this section asked about the frequency of participation in learning activities with patients related to health literacy. For nine questions, a Likert-type scale with responses of ( 1 = Never, 2 = Sometimes, $3=$ Frequently, and 4 = Always) was used. The questions examined frequency of 
use of health literacy in direct patient care, use as a screening tool, evaluation of reading level cultural appropriateness, evaluation in the use of illustrations, and frequency of use of written materials. Cronbach's alpha was 0.79 for Part I (Knowledge) and 0.76 for Part II (Experience) (Cormier, 2006). In a previous study, Cormier (2006) indicated that a criterion rating of 0.60 or better was considered a good estimate of internal consistency and reliability.

Part III of the questionnaire related to demographics of the respondents. Specifically, the questions concerned the age, gender, ethnicity, prior educational experience, grade point average, highest level of education obtained in nursing, educational experience, and the frequency of interaction with healthcare providers for their personal healthcare or for the healthcare of family members or friends. An added question was designed to describe the current program track in which senior nursing students are enrolled.

\section{Data Collection}

Data were collected during the Fall semester of 2014. Approval to administer the survey met the requirements of Institutional Review Boards of each institution. Nursing program administrators were contacted through emails, in which they received a copy of the recruitment/consent letter describing the research project and time required to complete the survey (i.e., 15-20 minutes) (Cormier, 2006; Knight, 2011). Nursing program administrators forwarded a copy of the recruitment/consent letter via email to their faculty. Then, the faculty members provided students with a copy of the recruitment/consent letter to accept or decline participation in the study. After identifying students agreeing to participate, they notified the investigator by email to schedule a time to administer the survey to students in class.

Although participation in the survey implied informed consent, the investigator provided each student with a second copy of the recruitment/consent letter to ensure that all had an opportunity to accept or decline participation in the study. During a classroom presentation, the investigator reviewed the entire recruitment/consent letter with students and explained the study population, including its purpose, procedure, alternatives to participation, anonymity of respondents, stored data, benefits and risks, if any.

After the presentation, the investigator distributed the survey to each student and emphasized that the alternative to participation was not to take the survey or stop taking the survey at any time. Also, the investigator informed participants that the completion time of the survey was estimated at 15-20 minutes. The participants were not informed that the survey was anonymous and that there was no incentive for completing the survey, nor would taking the survey impact their program enrollment stat. After receiving a comprehensive review of the study, most agreed to participate. The paper-and-pencil survey was administered at the end of a scheduled class time.

\section{Data Analysis}

Prior to data analysis, a data dictionary was created, the purpose of which was to describe and code data in numerical form for easy access to information. Data were entered using the SPSS version 22 (IBM. 2014). Descriptive statistics including means, frequencies, and percentages were used to describe the demographics.

Descriptive statistics (frequencies) were used to analyze demographic data. Means and standard deviations were used to analyze knowledge scores by participants in the same program. The instrument was tested for internal consistency and reliability by use of Cronbach's Alpha. The Cronbach's Alpha for Part I (Knowledge) was 0.79 and, on the Part II (Experience), was 0.77. A one-way analysis of variance (ANOVA) was conducted to assess for differences in the knowledge mean scores between program sites. Levene's test of homogeneity of variance showed that the variances were not equal. Therefore, the Welch ANOVA and GamesHowell post-hoc tests for multiple comparisons were used.

\section{RESULTS}

\section{Health Literacy Knowledge}

A total score was calculated for each content section on Part I of the HL-KES survey, which assessed health literacy knowledge. The content areas were: basic facts on health literacy, consequences of low health literacy, health literacy screenings, guidelines for written healthcare materials, and evaluation of health literacy interventions. Table 2 summarizes the means and standard deviations for each content area test of HL-KES for the sample as a whole as well as for each program. Variations in the standard deviation are reported for each program to detect differences in knowledge scores for participants in the same program.

As reflected in Table 2, on average, scores varied across the content areas. The students scored highest on the Guidelines portion of the test $(M=6.49, S D=1.88)$ and lowest on the Evaluate portion of the test $(M=1.71, S D=0.54)$. Furthermore, the least amount of variation across individual scores was found for the Evaluate content area (SD = 0.54); the greatest variation was found for the Guidelines content area $(\mathrm{SD}=1.88)$.

The average scores varied across the content areas for students in the same program. Little variation (small standard deviation) was found in lower limits (below the SD sample) of the standard deviation and higher variation for the upper limits (above the SD sample). These data were omitted from the output for Program 6 for HL-KES because the standard deviation was too small to compute. The assumption is that variations in knowledge scores were related to gaps in health literacy knowledge regardless of the participant's degree status. A conclusion is that there are differences in health literacy knowledge among senior nursing students in the same program. 


\begin{tabular}{|c|c|c|c|c|c|c|c|}
\hline \multirow{2}{*}{ Content Area } & & Basic Facts & Conseq & Health & Guideline & Evaluate & Total Score \\
\hline & & (6) & (4) & (6) & (11) & (2) & (29) \\
\hline Program Site & $N$ & $S D$ & $S D$ & $M \quad S D$ & $S D$ & $S D$ & $S D$ \\
\hline Program 1 & 38 & $3.66(1.30)$ & $3.13(0.81)$ & $3.53(1.01)$ & $6.42(2.05)$ & $1.74(0.50)$ & $18.47(3.42)$ \\
\hline Program 2 & 17 & $4.53(0.71)$ & $3.76(0.43)$ & $4.24(0.97)$ & $7.82(1.55)$ & $1.94(0.24)$ & $22.29(2.17)$ \\
\hline Program 3 & 29 & $3.34(1.59)$ & $2.97(1.12)$ & $2.83(1.00)$ & $5.59(0.79)$ & $1.28(0.79)$ & $16.00(4.64)$ \\
\hline Program 4 & 88 & $3.30(1.28)$ & $3.15(0.75)$ & $3.47(0.98)$ & $6.53(1.71)$ & $1.74(0.49)$ & $18.18(3.44)$ \\
\hline Program 5 & 20 & $3.05(1.31)$ & $3.21(0.81)$ & $3.45(1.01)$ & $6.65(1.73)$ & $2.00(0.00)^{*}$ & $21.55(2.80)$ \\
\hline Total & 192 & 3.46 (1.31) & $3.21(0.81)$ & 3.45 (1.01) & $6.49(1.88)$ & $1.71(0.54)$ & $18.63(3.90)$ \\
\hline
\end{tabular}

SD appears in parentheses $(*)$

\section{Health Literacy Knowledge by Program Sites}

Health literacy knowledge scores were also determined for senior nursing students at various program sites. Differences in these scores are reflected in Table 2. The one-way ANOVA results indicated that there are statistically significant differences in the mean scores for the program sites $(\mathrm{F}(4,187)=8.926, \mathrm{p}<=0.0005)$ (see Table 3). To determine which program sites were different, GamesHowell post-hoc testing was performed. This approach was used because the assumption of equal variances was violated. The results indicated that there are statistically significant differences between the mean health literacy knowledge scores of the groups. Statistically significant differences were noted for the Health Literacy scores between several sites: (a) Program 1 and 2, (b) Programs 1,2,3,4, and 5, (c) Programs 2, 3, and 5, and (d) Programs 2 and 4. Program 2 had the highest mean score $(M=22.29$, $\mathrm{SD}=2.17)$, and Program 3 had the lowest mean score $(\mathrm{M}=$ $16.00, \mathrm{SD}=4.64)$. Differences may exist between program sites because of differing gaps in health literacy knowledge of participants.

Table 3. One-Way Analysis of Variance of Health Literacy Knowledge by Program Sites

\begin{tabular}{|l|c|c|c|c|c|}
\hline Knowledge & Df & SS & MS & F & P \\
\hline Between groups & 4 & 429.34 & 107.33 & 8.926 & 0.0005 \\
\hline Within groups & 187 & 2248.64 & 12.03 & & \\
\hline Total & 191 & 2677.98 & & & \\
\hline
\end{tabular}

\section{Health Literacy Experiences}

Part II of the HL-KES was used to explore differences in health literacy experiences of the participants. The original survey consisted of the nine-item Health Literacy Experiences Scale. Table 4 shows the percentage frequency of health literacy experiences reported using the following scales: $6(3 \%)$ to $105(55 \%)=$ never, $60(31 \%)$ to $104(54 \%)$ = sometimes, $15(8 \%)$ to $89(46 \%)=$ frequently, and $4(2 \%)$ to $28(15 \%)=$ always. The results indicated that participants had been engaged in health literacy experiences less than $50 \%$ of the time while enrolled in the nursing program. Although a one-way ANOVA was used to assess statistically significant differences between the participants, statistical significance could not be determined. The results indicated that most of the responses were those of prelicensure nursing students who had no prior nursing experiences beyond the classroom. Only 5\% of responses represented RN and LPN/LVN participants. Results of a study by Macabasco-O'Connell and Fry-Bowers (2011) support our findings that less than $60 \%$ of nurses had not had any formal education or training about health literacy. However, the unequal sample sizes between groups may have affected the findings specific to health literacy experiences. 
Table 4. Percentage Frequency of Health Literacy Experiences among Senior Nursing Students

\begin{tabular}{|l|c|c|c|c|c|c|}
\hline \multicolumn{1}{|c|}{ Valid } & $\begin{array}{c}\text { How } \\
\text { Frequently } \\
\text { Health } \\
\text { Literacy } \\
\text { Emphasized }\end{array}$ & $\begin{array}{c}\text { How Often } \\
\text { Use of } \\
\text { Health } \\
\text { Literacy } \\
\text { Screenings }\end{array}$ & $\begin{array}{c}\text { How Often } \\
\text { Evaluate } \\
\text { Reading } \\
\text { Level }\end{array}$ & $\begin{array}{c}\text { How Often } \\
\text { Evaluate } \\
\text { Culture }\end{array}$ & $\begin{array}{c}\text { How Often } \\
\text { Evaluate } \\
\text { Use of } \\
\text { Illustrations }\end{array}$ & $\begin{array}{c}\text { How Often } \\
\text { Use Written } \\
\text { Materials }\end{array}$ \\
\hline Never & $\mathbf{N ~ ( \% )}$ & $\mathbf{N ~ ( \% )}$ & $\mathbf{N ~ ( \% )}$ & $\mathbf{N}(\%)$ & $\mathbf{N}(\%)$ & N (\%) \\
\hline Sometimes & $68(3)$ & $105(55)$ & $71(37)$ & $33(17)$ & $35(18)$ & $14(7)$ \\
\hline Frequently & $73(38)$ & $68(35)$ & $86(45)$ & $104(54)$ & $86(45)$ & $60(31)$ \\
\hline Always & $15(8)$ & $4(2)$ & $10(5)$ & $11(6)$ & $11(6)$ & $28(15)$ \\
\hline & & & $25(13)$ & $44(23)$ & $60(31)$ & $89(46)$ \\
\hline Total & $192(100)$ & $192(100)$ & $192(100)$ & $192(100)$ & $192(100)$ & $192(100)$ \\
\hline
\end{tabular}

\section{DISCUSSION}

Regardless of the nursing program or degree-type, senior nursing students have differences in health literacy knowledge, whether they are in the same program or at a different program site. The results from the health literacy experiences portion of the survey did not yield significant differences due to the limited clinical experiences of the respondents.

There were differences in health literacy knowledge for participants at the same program site. Although previous reports show similarities in characteristics of nursing students, the present findings are consistent with other results assessing health literacy knowledge (Cormier \& Kotrlik, 2009; Knight, 2012). Although there was variation in health literacy scores among participants at the same program site, the variation may be due to differences in exposure to the concept of health literacy either in the nursing curriculum or elsewhere (Cormier \& Kotrlik, 2009; Coleman, 2011).

There are differences in health literacy knowledge among participants enrolled at different program sites. The results varied across content areas and were evident in the sections on health literacy screening, guidelines for written health care materials, and evaluation of health literacy interventions. Across program sites, the highest score on HL-KES knowledge portion was 29. Five program sites had scores between $55 \%-75 \%$ for the section on health literacy knowledge. A possible explanation for gaps in health literacy knowledge across programs is that participants had not been fully exposed to health literacy concepts in their nursing curriculum. (Sand-Jecklin, et al., 2010; Coleman, 2011; McClearly-Jones, 2012). The present results are consistent with the previous literature. Nursing students have increased health literacy knowledge, perceptions, and experiences when they are exposed to education and training in this field (McClearly-Jones, 2012).

For each program, there was a mixture of participants by type of degree (Table 6). Pre-licensure participants represented $95 \%$ of the sample. One program site had an enrollment of 17 senior nursing students; other sites enrolled between 29-88 students. Program sites with fewer students scored higher $(M=22.29, S D=2.17)$ in the six health literacy knowledge content areas than those in programs with a larger student enrollment. Those at the program site that scored highest had received a presentation related to the research and background information on the importance of health literacy. Perhaps the presentation resulted in bias, in that the students received health literacy knowledge before taking the survey. Also, the program that scored lowest $(M=16.00, S D=4.64)$ on the health literacy knowledge section had distractions and time constraints. For example, when the class ended, most of the senior nursing students left the classroom. Those participants agreeing to take the survey completed it during a tutorial session in preparation for the nursing licensure exam in December. Attrition was very high because most students from the previous class did not attend the tutorial session. Only those senior nursing students attending the tutorial session volunteered to participate in the survey. The survey was administered to participants before and during the tutorial session. Therefore, participants' did not have sufficient time to focus on the survey questions, and that may have biased their results. Further qualitative research is needed to understand the current nursing curriculum and challenges nursing programs have with addressing health literacy.

Moreover, participants in the current study indicated having limited experiences with health literacy interventions. For these student nurses, any experiences took place during their clinical placements, which averaged to one semester at the time data were collected. Since the results indicated that most of the participants had little exposure to health literacy training and practices, the integration of health literacy into the nursing curriculum is an effective way to educate nursing students about health literacy interventions (Cornett, 2009; McCleary \& Jones, 2012; Novitzky, 2009). Training faculty members in health literacy strategies is imperative for the delivery of health literacy education to students. Based on the present findings, these senior nursing students will enter the nursing profession with gaps in knowledge and limited experiences with health literacy. It appears that health literacy is not being addressed in the nursing curriculum at most sites. 
Since senior nursing students have differing health literacy knowledge and experiences, consistency in training and education is necessary for improving patient education. Thus, nursing programs should integrate health literacy content into the nursing curriculum (Cormier \& Kotrlik, 2009; Hartman, 2014). Addressing knowledge gaps early in the education of nurses could improve their ability to recognize low health literacy when working with patients.

For the present study, there are several limitations, most of which are inherent in quantitative research (Creswell, 1994). For instance, the convenience sampling and small numbers of each group limit generalization to larger populations. Participation was voluntary. Participants consisted of senior nursing students who were currently enrolled in an accredited nursing program and may have had no prior knowledge or experiences with health literacy interventions. Since the survey was administered near the end of classes, participants may have rushed to complete it. In the classroom setting, some may have had difficulty in responding because of noise and other distractions. Further, the samples of RN and LPN/LVN participants were too small to compare to pre-licensure participants. Data analysis methods were limited to means and standard deviations to observe variations in knowledge scores among participants. Further qualitative research is recommended to gather more information about health literacy knowledge and experiences of the participants.

Whereas low health literacy knowledge among the current study participants is associated with gaps in knowledge, training and education can eliminate these gaps. In sum, the results contribute to an emerging body of literature examining the health literacy knowledge and experiences of nursing students. A recommendation is to incorporate health literacy into the nursing curriculum.

The findings of previous studies (Cormier \& Kotrlik, 2009; Hartman, 2014) related to health literacy research using the HL-KES and other theoretical frameworks are consistent with the present results. The present study, examining differences in health literacy knowledge and experiences of senior nursing students before they enter the workforce, shows that gaps in knowledge and experiences for nursing students continue to exist.

\section{Implications for Public Health}

As the nation undergoes a paradigm shift in public health, the need for nursing students to be prepared to provide effective health literacy interventions should be a national priority. It is appropriate to educate and train senior nursing students in the application of health literacy strategies. A lack of education and training limits their knowledge and experiences about the impact of low health literacy on public health practice (Richey, 2007). The Institute on Medicine (IOM, 2010) report, The Future of Nursing Leading to Change and Advancing Health calls for nurses to practice to the fullest extent of their education and training, and for nurses to be full partners with physicians and other healthcare professionals in redesigning healthcare in the United States. Since patients are not required to undergo literacy testing, nurses should be knowledgeable about ways to recognize low health literacy in patients (Ferguson, et al., 2011).

Nursing students and other healthcare professionals have been designated as key staff to address the problem of low health literacy, and improving health outcomes for patients is a goal in community health education and health promotion practices. Therefore, the issue of low health literacy should be raised so that other institutions recognize it as a problem and advocate for incorporating health literacy into the nursing curriculum.

Acknowledgements to Moya A. Alfonso and John S. Luque for their contributions in critiquing the dissertation prior to submission of this manuscript.

\section{References}

Agency for Health Care Research and Quality Report (2010). Health Literacy Universal Toolkit. Retrieved from https://www.ahrq.gov/clinic/epcsums/litsum.htm

Alper, J., Rapporteur, Roundtable on Health Literacy; Board on Population Health \& Public Health Practice; Institute on Medicine; The National Academies of Sciences; Engineering and Medicine. (2015). Health literacy: Past, present, and future: Workshop summary. Washington, DC: National Academy Press (US).

Cafiero, M. R. (2012). Nurse practitioners' knowledge, experience and intentions to use health literacy strategies in practice. Journal of Health Communications: International Perspectives, $18,70-81$.

Coleman, C. (2011). Teaching healthcare professions on improving health literacy: A review of the literature. Nursing Outlook, 59, 70-80.

Cooper, L. (2011). Health literacy and health disparities: Opportunities for trans-disciplinary collaboration. In Innovations in health literacy workshop summary (Chapter 3). Washington, DC: The National Academies Press.

Cormier, C.M. (2006). Health literacy: Knowledge and experiences of senior level baccalaureate nursing students. Doctoral dissertation, Retrieved from: http://etd.lsu.edu/docs/available/etd-11072006153104/unrestricted/Cormier_dis.pdf

Cormier, C. M., \& Kotrlik, J. W. (2009). Health literacy knowledge and experience of senior baccalaureate students. Journal of Nursing Education, 48, 237-248.

Cornett, S. (2009). Addressing health literacy. Online Journal of Issues in Nursing, 14, 1-14.

Creswell, J. (1994). Research design: Qualitative \& quantitative approaches. Thousand Oaks: Sage Publication.

Ferguson, L.A. \& Pawlak, R. (2011). Health literacy: The road to improve health outcomes. The Journal of Nurse Practitioners, 7, 123-129.

Hartman, E. (2014). Nurses lack skills to teach: Increasing undergraduate nursing skills related to patient education. (Doctoral dissertation). Retrieved from ProQuest Dissertations and Theses. (Accession Order No. AAT 36117830).

Healthy People. (2014, January 24). Health Information and Health Technology. Retrieved from http://www.healthypeople.gov/2020/topicsobjectives2020 /overview.aspx?topicid $=18$

Institute of Medicine (IOM). (2004). Health literacy: A prescription to end confusion. Washington, DC: National Academic Press. Retrieved from http://www. iom.edu/report.asp?id=19723

Institute of Medicine (IOM). (2010). The future of nurses: Leading change, advancing health. Washington, DC: National Academic Press. Retrieved from http://www.iom.edu/Reports/2010/Thefuture-of-nursing-leading-change-advancing-health.aspx 
Knight, G. D. (2012). An evaluation of the health literacy knowledge and experiences of registered nurses in Georgia. (Doctoral dissertation, Auburn University). Retrieved from http://etd.auburn.edu/etd/bitstream/handle/10415/2460/Glenda_ Knight_Dissertation_Dec_2010_2.pdf?s

Macabasco-O’Connell, A., \& Fry-Bowers, E. K. (2011). Knowledge and perception of health literacy among nursing professionals. Journal of Health Communication, 16, 295-307.

McCleary, V. (2012). Assessing nursing students’ knowledge of health literacy. Nurse Educator, 37, 214-217.

Novitzky, Jan. (2009). Towards a health literacy curriculum. Retrieved from https://www.eric.ed.gov.

Owens, L., \& Walden, D. (2007). Health literacy: The new essential in nursing education. Nurse Educator, 32, 238-239.

Paache-Orlow, M. K., \& Wolf, M. S. (2007). The causal pathways linking health literacy to health outcomes. American Journal of Health Behavior, 31, S19-S26.

Ratzan, S. C. (2011). Health literacy: Building upon a strong foundation. Journal of Health Communication, 16, 3-4.

Richey, M. (2012). Registered nurses' perception of health literacy and its effects on patient self-efficacy and patient healthcare. Retrieved from http://gateway.proquest.com/openurl?url_ver=Z39.882004\&res_dat=xri:pqdiss\&rft_val_fmt=info:ofi/fmt:kev:mtx:dis sertation\&rft_dat=xri:pqdiss:3545855

Rudd, R. E., \& Moeykens, B. A. (1999). Findings from a national survey of adult educators: Health and literacy. Cambridge, MA: NCSALL.

Rudd, R., \& Anderson, J. (2006). The health literacy environment of hospitals and health centers. Retrieved from https://www.hsph.harvard.edu/healtliteracy/files/ healthliteracyenvironment.pdf

Rush, S .R. \& Paasche-Orlow, M. K. (2011). Incorporating health literacy into larger operational environments. Journal of Health Communications, 16, 9-10.

Sand-Jecklin, K., Murray, B., Summers, B., \& Watson, J. (2010) Educating nursing students about health literacy: From the classroom to the patient bedside. The Online Journal of Issues in Nursing, 15, 1-10.

Scheckel, M., Emery, N., \& Nosek, C. (2010). Addressing health literacy: The experiences of undergraduate nursing students. Journal of Clinical Nursing, 5, 794-802.

Singleton, K., Krause, E. (2009). Understanding cultural and linguistic barriers to health literacy. The Online Journal of Issues in Nursing, 14, 1-25.

Smith, J., \& Zsohar, H. (2011). Teaching health literacy in the undergraduate curriculum: Beyond traditional methods. Nursing Education Perspectives, 32, 48-50.

The Joint Commission. (2007). What did the doctor say? Improving health literacy to protect patient safety. Oakbrook Terrace, IL: Joint Commission on Accreditation of Health Care Organizations. Retrieved from http://www.jointcommission. org/What_Did_the_Doctor_Say?/

The Joint Commission. (2010). New patient safety goals. Oakbrook Terrace, ILO: The Joint Commission on Accreditation of Health Care Organizations. Retrieved from http://www.jointcommission.org/standards_information/npsgs.as $\mathrm{px}$ 